\title{
Comparative Analysis Of Voltage Source Inverter Using Sinusoidal Pulse Width Modulation And Third Harmonic Injection Method For Different Levels And Loads
}

\author{
Sandeep Ojha \\ PG Scholar Department of Electrical Engineering Madan Mohan Malaviya University Of Technology Gorakhpur
}

Ashok Kumar Pandey

Associate Professor Department of Electrical Engineering Madan Mohan Malaviya University Of Technology Gorakhpur

\begin{abstract}
This paper presents a comparative analysis of Voltage Source Inverter using Sinusoidal Pulse Width Modulation Method and Third Harmonic Injection Pulse Width Modulation Method in Two and Three level inverter for different loads. In this paper we have designed the Simulink model of Inverter. All above technique is used to reduce the Total Harmonic Distortion (THD) on the AC side of the Inverter. Results are analyzed using Fast Fourier Transformation (FFT) analysis for observing the Total Harmonic Distortion. All simulation are performed in the MATLAB Simulink.
\end{abstract}

Keyword: Voltage Source Inverter (VSI), Sinusoidal Pulse Width Modulation (SPWM), Third Harmonic Injection Pulse Width Modulation (THIPWM).

\section{Introduction}

A circuit which converts DC power into an AC power at desired output Voltage and Frequency is known as Inverter. A phase controlled converter, when it is used in inverter mode, are known as line-commutated Inverter, only line-commutated inverter requires at the output terminals an existing AC supply which is used for their commutation. A Force commutated Inverter gives an independent AC output voltage of adjustable Voltage and Frequency, therefore its application is vast. In Inverter we require Forced commutation for thyristor, therefore we can use other self-commutating device like GTO, MOSFET, and other Transistors to avoid the commutation circuit. But for high power application we must use thyristor along with the forced commutation circuit. There are total four techniques to reduce the Total Harmonic Distortion in Inverter

1. Sinusoidal Pulse Width Modulation

2. Third Harmonic Injection Method

3. Delta Method ( $60^{\circ}$ Pulse modulation )

4. Space Vector Pulse Width Modulatio

In this paper we focus on the Sinusoidal pulse width technique and Third harmonic injection technique

\section{SINUSOIDAL PULSE WIDTH MODULATION}

This technique is very useful for reducing the Total Harmonic Distortion. This technique is characterized by the constant amplitude pulse. And the width of these pulse is modulated to get Inverter output Voltage control and to reduce its harmonic content. Force commutation is essential for the pulse width modulation. The Switching sequences and topology of the Inverter is same. In this technique the Gate pulse of MOSFET is modulated and control the Switching of MOSFET to get the desired output voltage for input voltage of Induction motor.

Fourier analysis of the voltage waveform and get the output voltage of Inverter.

$\mathrm{V}(\mathrm{t})=\mathrm{A}_{0}+2 *\left[\sum_{k=1}^{\infty} A k * \cos k w t+B k * \sin k w t\right]$

The output voltage wave is odd symmetry. So, $\mathrm{A}_{0}$ andAk is zero. So,

$\mathrm{Bk}=(2 / \pi)^{*}\left[\int_{\frac{\pi}{2}-d}^{\frac{\pi}{2}+d} V s * \sin (n w t) d(w t)\right]$

$=((4 * V s) /(\mathrm{n} \pi)) *[\sin (\mathrm{n} \pi / 2) *$

$\sin (\mathrm{nd})]$

$\mathrm{V}_{0}=\left(\sum_{n=1,3,5}^{\infty}\left[\left(\frac{4 V s}{n \pi}\right) * \sin \left(\frac{n \pi}{2}\right) * \sin (n d) * \sin (n w t)\right]\right)$

nd is made equal to $\pi$. So, $d=(\pi / n)$

So, the pulse width is made $2 \mathrm{~d}$ and that is equal to $(2 \mathrm{~d} / \mathrm{n})$.

Where $\mathrm{n}^{\text {th }}$ is the harmonic is eliminated from the inverter output voltage.

In the Simulink model sine wave frequency is $50 \mathrm{~Hz}$ and the amplitude of the sine wave is 5; and carrier frequency is sawtooth with frequency is $1000 \mathrm{~Hz}$.

\section{THIRD HARMONIC INJECTION PULSE WIDTH MODULATION METHOD}

This method is also a very useful method for eliminating the harmonic in the system which comes due to the MOSFET or power electronic switches. In this method we inject the third harmonic in the system and control the pulse of the MOSFET. To get the harmonic free inverter output voltage. To find the 
amplitude of the third harmonic of unknown amplitude of the third harmonic component.

So let us take simple sine wave whose fundamental frequency is $50 \mathrm{~Hz}$ with the third harmonic of unknown amplitude $\mathrm{x}$.

$Y(\alpha)=\sin (\alpha)+x^{*} \sin (3 \alpha)$

For finding the maximum value of the function $\mathrm{d} / \mathrm{d} \alpha(\mathrm{Y}(\alpha))$ $=0$

Which gives,

$\alpha=\cos ^{-1} \sqrt{((9 x-1) /(12 x))}$

From equation (3) and (4)

$\mathrm{F}(\mathrm{x})=\mathrm{Y}(\alpha)=[(3 \mathrm{x}+1)(\sqrt{(3 x+1) /(12 x)}-$

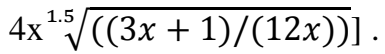

For finding the maximum value of equation (5) using formula $\mathrm{d} / \mathrm{dx}(\mathrm{F}(\mathrm{x}))$

So we get $\mathrm{x}=-0.334,0.1667$

At $x=-0.334$

$\mathrm{d}^{2} / \mathrm{dx} \mathrm{x}^{2}(\mathrm{~F}(\mathrm{x}))=0$

At $\mathrm{x}=0.1667$

$\mathrm{d}^{2} / \mathrm{dx}^{2}(\mathrm{~F}(\mathrm{x}))=10.3923$

Which shows the given function is minimum. At $\mathrm{x}=0.1667$ the value of $\alpha$ is $60^{\circ}$

Now putting the value of $\alpha$ at $\mathrm{x}=0.1667$

$\mathrm{d}^{2} / \mathrm{dx}^{2}(\mathrm{Y}(\alpha))=-2$

This shows the function $Y(\alpha)$ is maximum.

So this is clear that the third harmonic should be 0.1667 of the amplitude of the ${ }_{d}$

Putting the value of $x=0.1667$ and $\alpha=60^{\circ}$ in equation (4)

Which gives $\mathrm{Y}(\alpha)=0.866025$, which is the peak of resultant waveform with third harmonic. And the modulation factor of $1 / 0.866025$ is 1.15470053 giving $15.47 \%$ more DC bus utilization.

$V a \quad V \sin (\alpha)$
$V b=V \sin \left(\alpha-120^{\circ}\right)$
$V c \quad V \sin \left(\alpha+120^{\circ}\right)$

Where,

$\mathrm{V}$ is Instantaneous Magnitude of fundamental

And

$\alpha$ is instantaneous phase of fundamental

For direct axis voltage and quadrature axis voltage using the equation

$\mathrm{Va}=0.667 * \mathrm{~V}_{\mathrm{q}} * \cos \beta+0.667 * \mathrm{~V}_{\mathrm{d}} * \sin \beta$

$\mathrm{Vb}=0.33 * \mathrm{~V}_{\mathrm{q}} * \sin \beta-0.5773 * \mathrm{~V}_{\mathrm{d}} * \cos \beta$

$\mathrm{Vc}=-\mathrm{Va}-\mathrm{Vb}$

Where,

$\mathrm{Va}$ is phase a voltage

$\mathrm{Vb}$ is phase $\mathrm{b}$ voltage

$\mathrm{Vc}$ is phase $\mathrm{c}$ voltage

$\mathrm{V}_{\mathrm{d}}$ is direct axis voltage

$\mathrm{V}_{\mathrm{q}}$ is quadrature axis voltage

From equation (6), (7), (8), and (9)
Instantaneous magnitude of fundamental waveform is

$\mathrm{V}=\sqrt{(\mathrm{Vq} 2}+\mathrm{Vd} 2) / 1.5$

Now we find the value of $\sin (\alpha)$ from equation (6)

We get $\sin (\alpha)=\mathrm{Va} / \mathrm{V}$

From equation (10) and (11) instantaneous third harmonic value is calculated

$\mathrm{V}_{\text {ref }}=(\mathrm{v} / 6) * \sin (3 \alpha)$

So phase voltage of third harmonic injection written as

$\mathrm{Va}_{\mathrm{THI}}=\left(\mathrm{Va}+\mathrm{V}_{\text {ref }}\right) * 1.1547$

$\mathrm{Vb}_{\mathrm{THI}}=\left(\mathrm{Vb}+\mathrm{V}_{\text {ref }}\right) * 1.1547$

$\mathrm{Vc}_{\mathrm{THI}}=\left(\mathrm{Vc}+\mathrm{V}_{\mathrm{ref}}\right) * 1.1547$.

The above equation give the information about the amplitude of the output phase voltage is 1.15 times of the normal output phase voltage. In the Simulink model sine wave frequency is $50 \mathrm{~Hz}$ and the amplitude of the sine wave is 5; and carrier frequency is sawtooth with frequency is $1000 \mathrm{~Hz}$. And additional sine wave is added to add the third harmonic in the Inverter whose sine wave amplitude is $5 / 3$ and its frequency is 3 times of rated frequency.

\section{TWO LEVEL INVERTER}

In this mode each MOSFET conducts for $180^{\circ}$ of a periodic cycle. Each phase has a pair S1, S4; S3, S6;S5, S2 and each trigger for $180^{\circ}$ of time interval. And

S1, S3, and S5 conduct at an interval of $120^{\circ}$. Refer to Fig 1. $0^{\circ} 60^{\circ} 120^{\circ} 180^{\circ} 240^{\circ} 300^{\circ} 360^{\circ}$

\begin{tabular}{|l|l|l|l|l|}
\hline S1 & \multicolumn{2}{l|}{ S3 } & S5 \\
\hline S6 & S2 & S4 & S6 \\
\hline
\end{tabular}

Fig 1:-Switching period of MOSFET.

Specification for pulse generator of $180^{\circ}$ mode VSI. Refer to Table 1.

Table 1:-For $50 \mathrm{~Hz}$ frequency Pulse Generator where amplitude $=\mathbf{5}$ and pulse width $\mathbf{5 0 \%}$.

\begin{tabular}{|l|l|}
\hline S1 & Phase Delay $=0 \mathrm{msec}$ \\
\hline S4 & Phase Delay $=10 \mathrm{msec}$ \\
\hline S3 & Phase Delay $=6.667 \mathrm{msec}$ \\
\hline S6 & Phase Delay $=16.667 \mathrm{msec}$ \\
\hline S5 & Phase Delay $=13.33 \mathrm{msec}$ \\
\hline S2 & Phase Delay $=23.33 \mathrm{msec}$ \\
\hline
\end{tabular}

\section{THREE LEVEL INVERTER}

This method is most useful method to eliminate the Harmonic in the system. In this level inverter one leg of the inverter consist Four MOSFET, and there is total three leg so total number of MOSFET is twelve. The basic formula of one leg consist of MOSFET is $2 *(n-1)$, where $n$ is the number of level.

In this three phase Three level inverter total twelve MOSFET. So, number of sectors are divided into Twelve sectors and one sector is of $30^{\circ}$. 
No. of sectors $=\left(360^{\circ} / 12\right)=30^{\circ}$.

Pulse width of S1 MOSFET is $41.667 \%$.

And for S4 the pulse width is $58.33 \%$

Similarly second and third leg MOSFET is $120^{\circ}$ and $240^{\circ}$ apart of corresponding MOSFET of first leg respectively. The repeating sequence that is triangular output value is 0 to 4.1667 and other is 4.1667 to 10 .

For sector table of first limb. Refer to Table 2.

Table 2:-Switching sectors of one leg MOSFET

\begin{tabular}{|l|c|c|c|c|}
\hline Sector Degree / MOSFET & S1 & S4 & S1 $^{\prime}$ & S4 $^{\prime}$ \\
\hline $0^{\circ}-30^{\circ}$ & 1 & 1 & 0 & 0 \\
\hline $30^{\circ}-60^{\circ}$ & 1 & 1 & 0 & 0 \\
\hline $60^{\circ}-90^{\circ}$ & 1 & 1 & 0 & 0 \\
\hline $90^{\circ}-120^{\circ}$ & 1 & 1 & 0 & 0 \\
\hline $120^{\circ}-150^{\circ}$ & 1 & 1 & 0 & 0 \\
\hline $150^{\circ}-180^{\circ}$ & 0 & 1 & 1 & 0 \\
\hline $180^{\circ}-210^{\circ}$ & 0 & 0 & 1 & 1 \\
\hline $210^{\circ}-240^{\circ}$ & 0 & 0 & 1 & 1 \\
\hline $240^{\circ}-270^{\circ}$ & 0 & 0 & 1 & 1 \\
\hline $270^{\circ}-300^{\circ}$ & 0 & 0 & 1 & 1 \\
\hline $300^{\circ}-330^{\circ}$ & 0 & 0 & 1 & 1 \\
\hline $330^{\circ}-360^{\circ}$ & 0 & 1 & 1 & 0 \\
\hline
\end{tabular}

In this Simulink model we added the bias in the sine wave whose value is 5 .

\section{SIMULATION MODEL PARAMETER}

Specification of model. Refer Table 3.

Table 3:-Model parameter and Specification

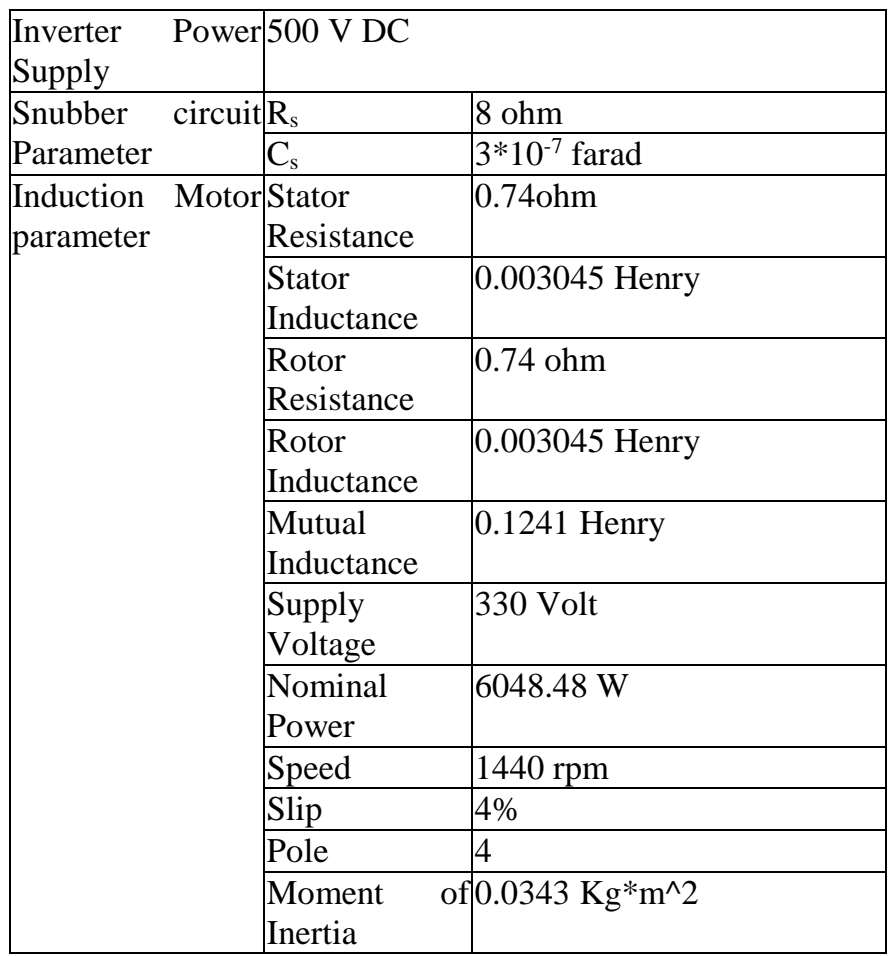

\begin{tabular}{|l|l|l|}
\hline \multirow{2}{*}{} & $\begin{array}{l}\text { Friction } \\
\text { Factor }\end{array}$ & 0.000503 N.m.s \\
\cline { 2 - 3 } & Load Torque & 35.53 N.m \\
\cline { 2 - 3 } & Efficiency & $88.54 \%$ \\
\hline \multirow{2}{*}{$\begin{array}{l}\text { plectrical } \\
\text { parameter }\end{array}$} & R load & 10 ohm \\
\cline { 2 - 3 } & R L load & 10 ohm,0.038216 Henry \\
\cline { 2 - 3 } & R L C load & $\begin{array}{l}10 \text { ohm, 0.038216Henry, } \\
2.274^{*} 10^{\wedge}-4 \text { Farad }\end{array}$ \\
\hline
\end{tabular}

\section{SIMULINK MODEL AND WAVEFORM:}

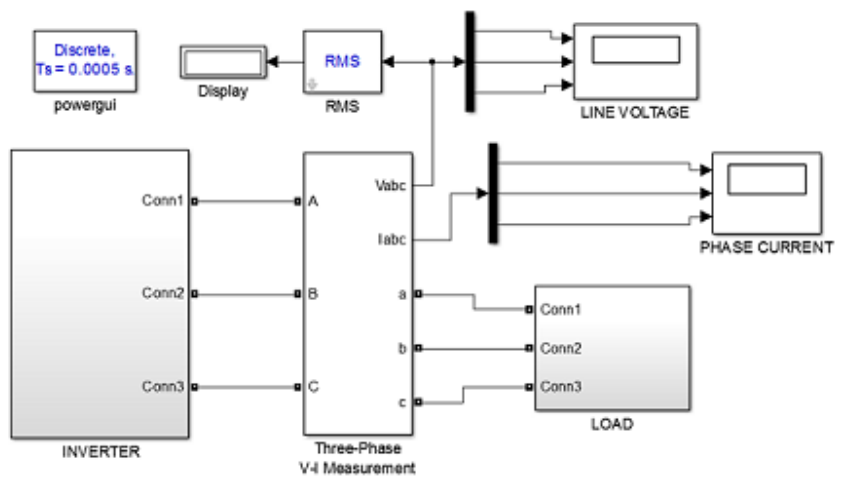

Fig 2:-Inverter with Load

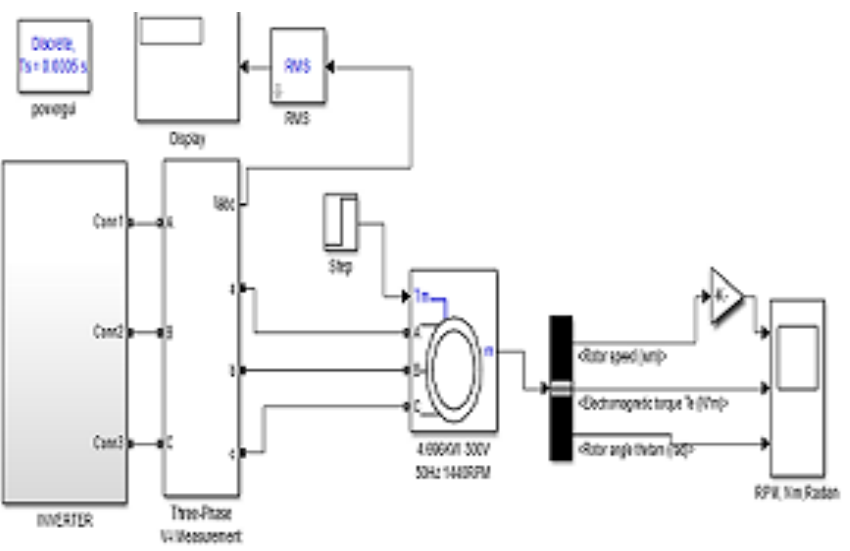

Fig 3:-Inverter with squirrel Cage Induction Motor

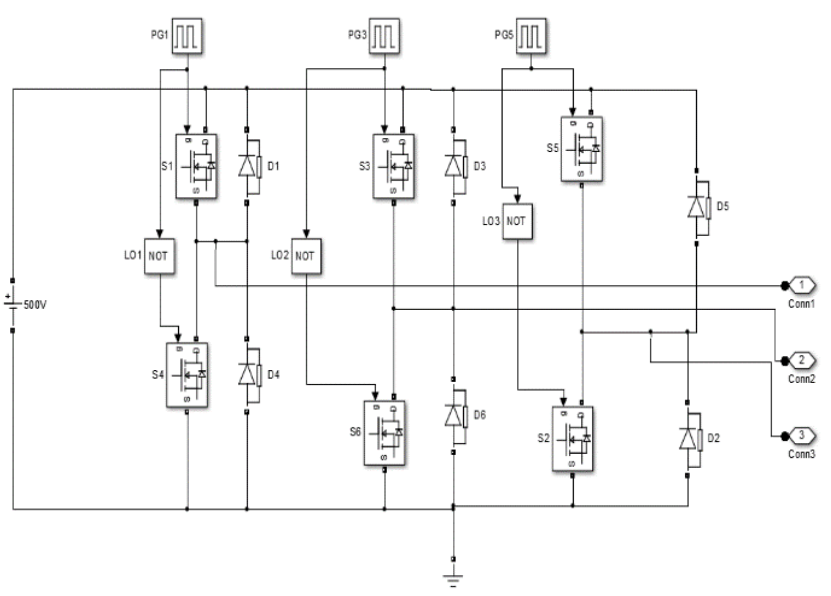

Fig 4:-Two level Inverter 


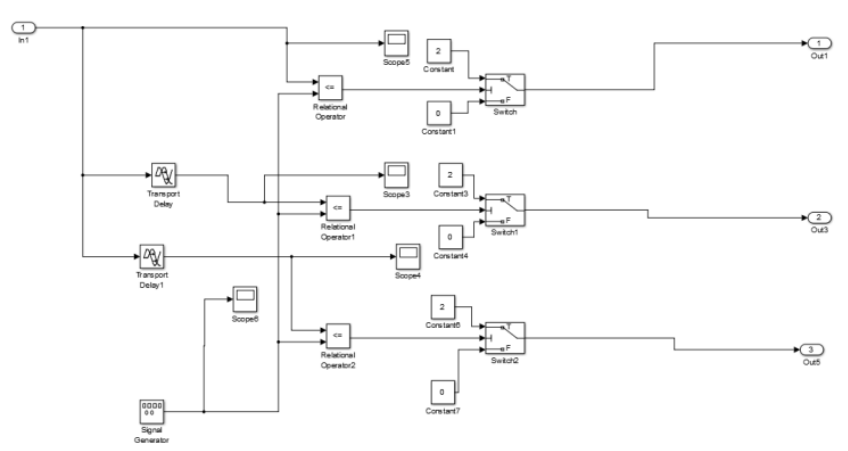

Fig 5:-Two level SPWM Inverter

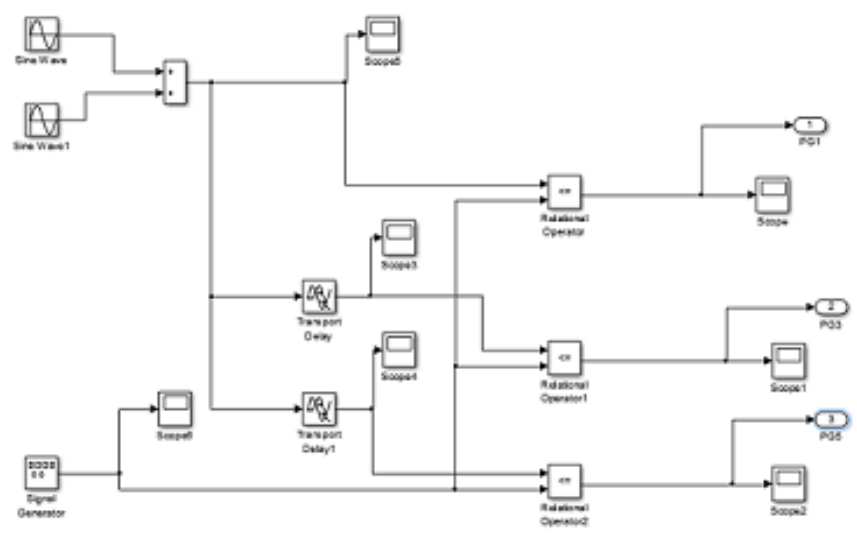

Fig 6:-Two level THIPWM Inverter

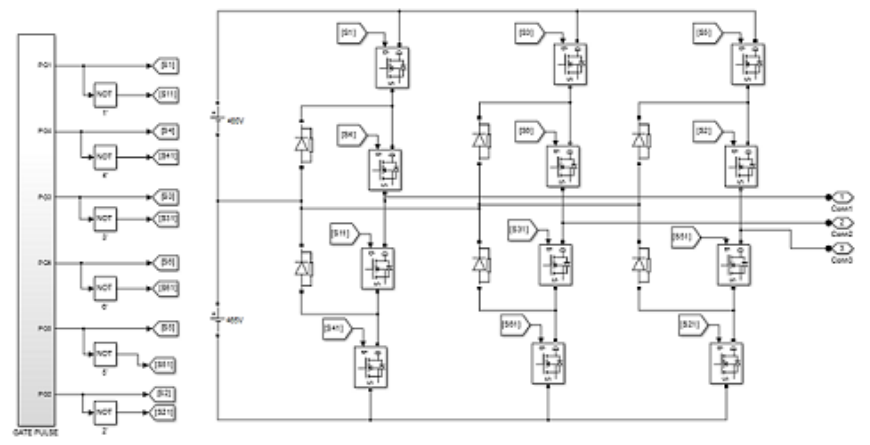

Fig 7:-Three level Inverter

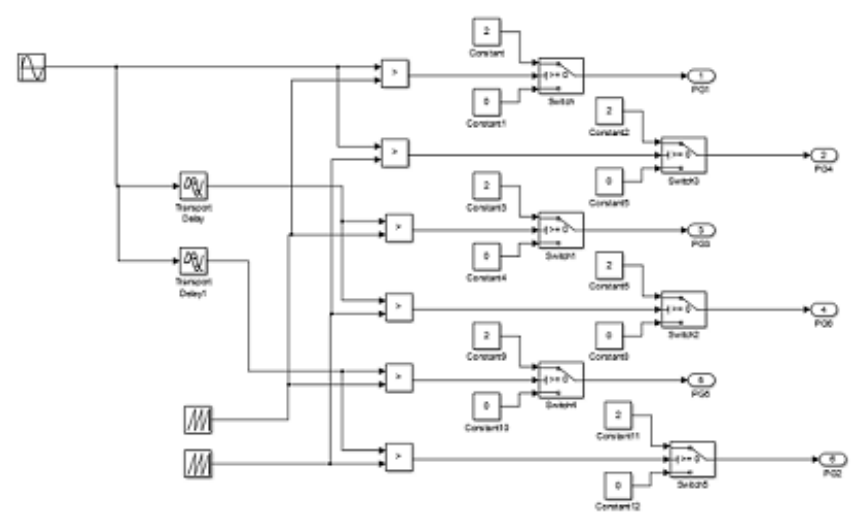

Fig 8:-Three level SPWM Inverter

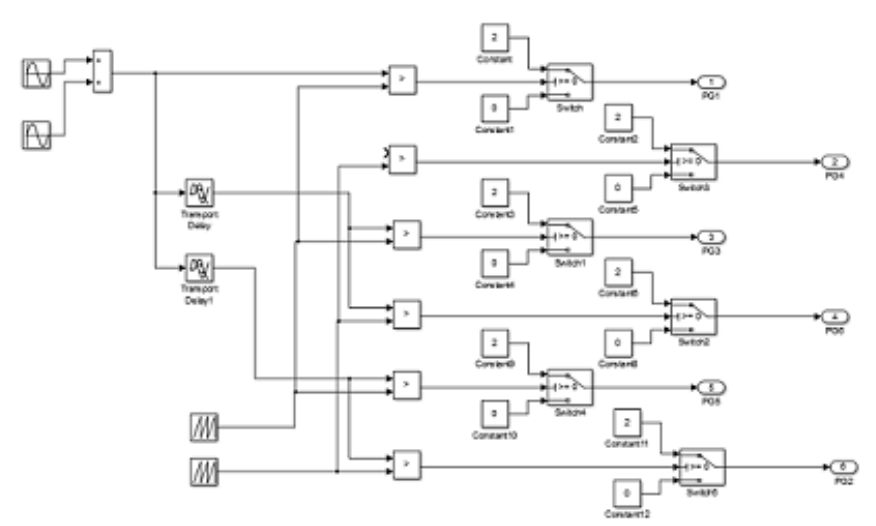

Fig 9:-Three level THIPWM Inverter

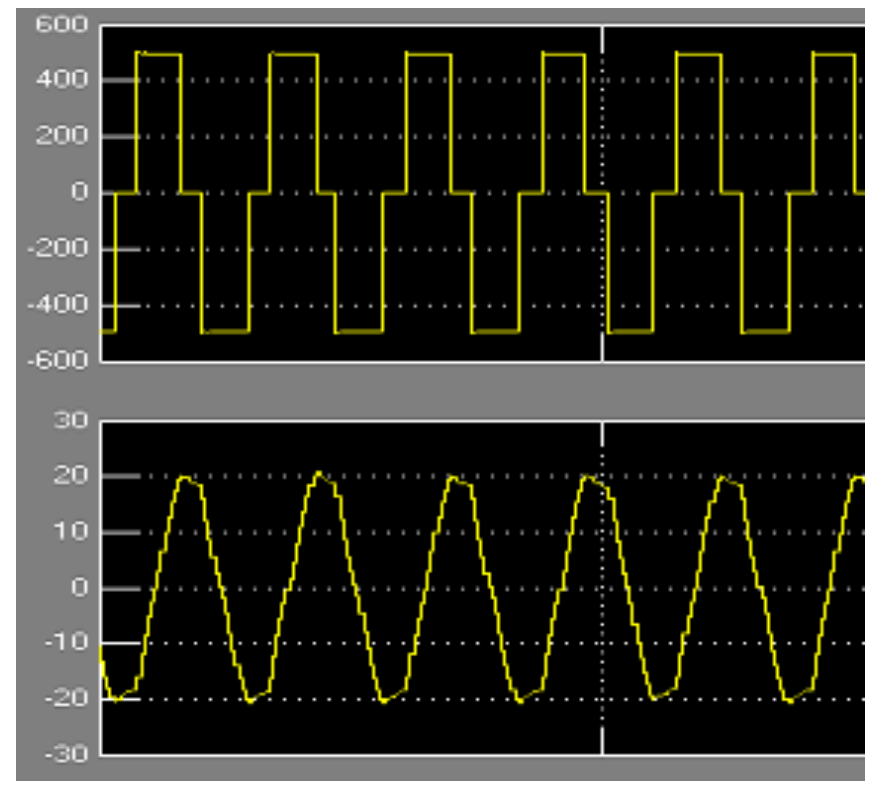

Fig 10:-Two level SPWM INVERTER RL load Line Voltage and Current

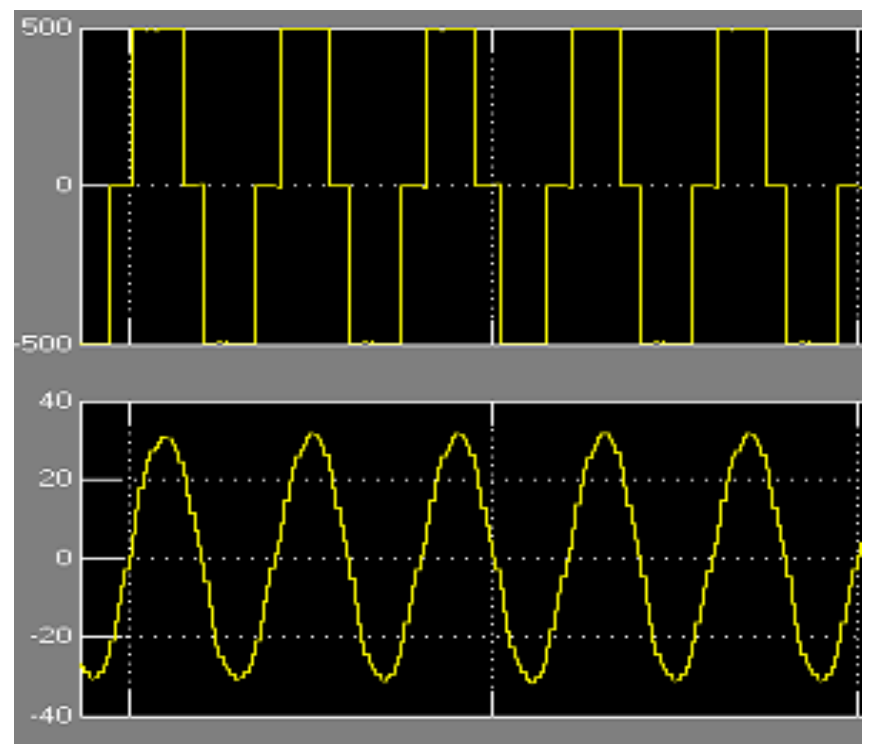

Fig 11:-Two level SPW M INVERTER RLC load Line Voltage and Current 


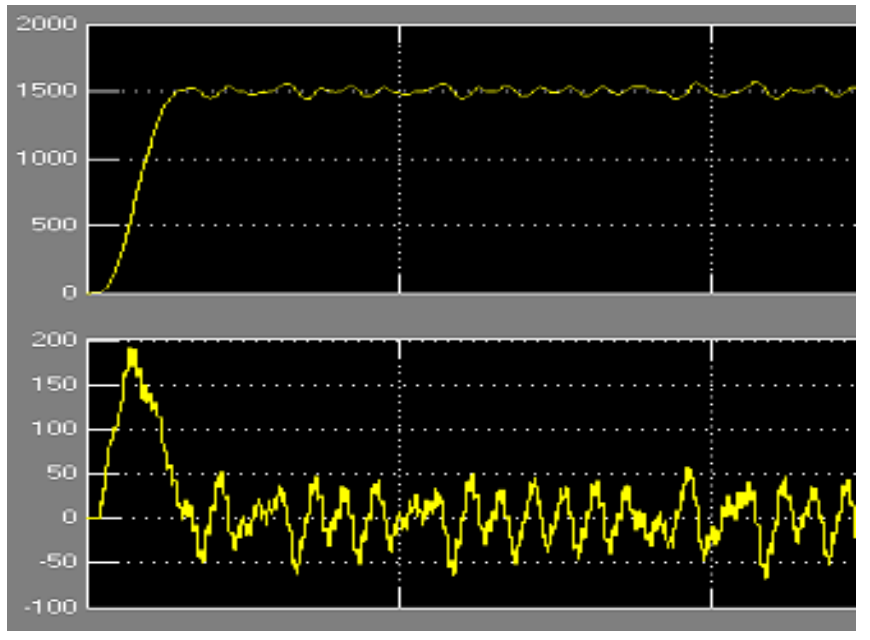

Fig 12:-Two level SPWM INVERTER Speed and Torque

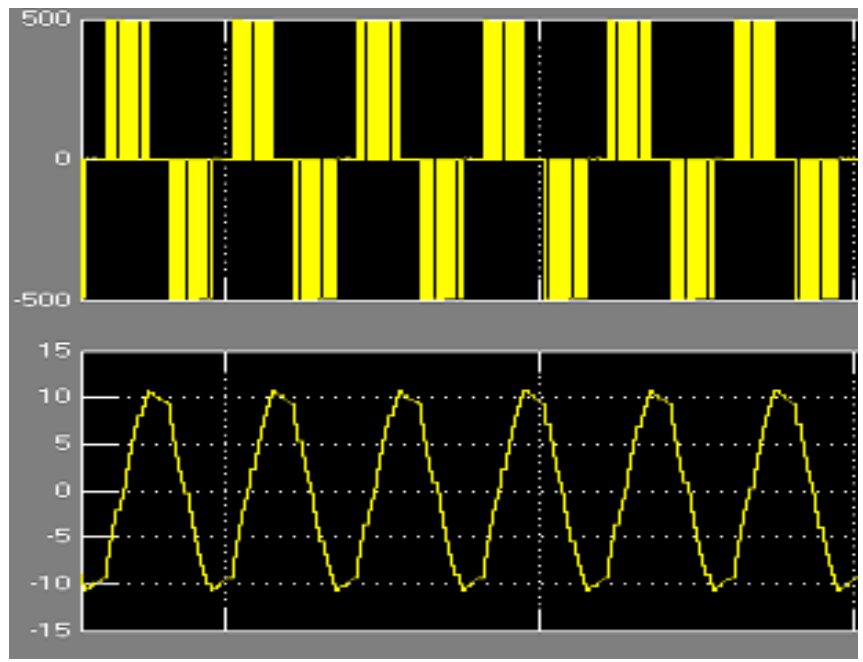

Fig 13:-Two level THIM INVERTER RL load Line Voltage and Current

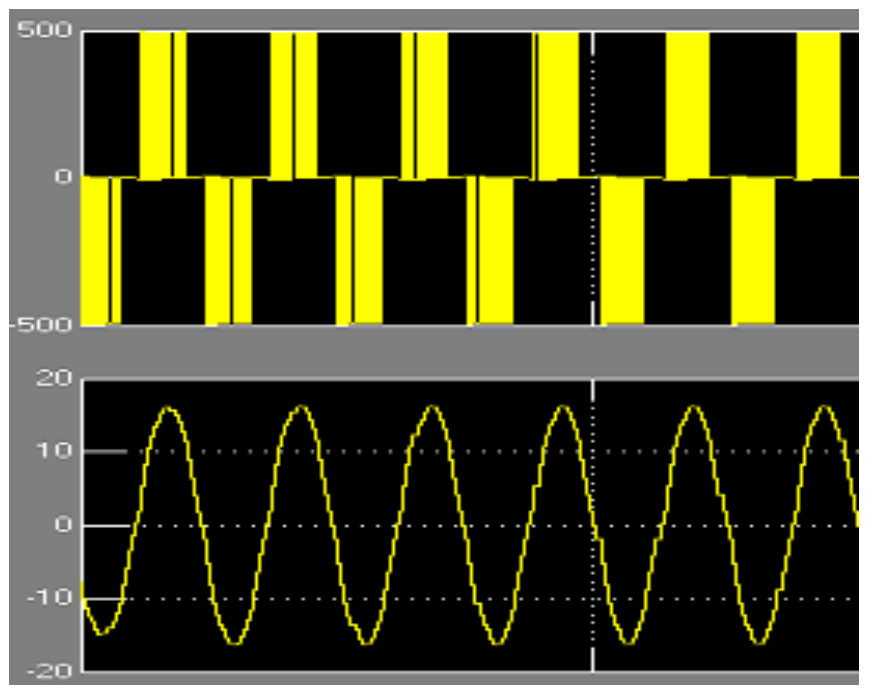

Fig 14:-Two level THIM INVERTER RLC load Line Voltage and Current

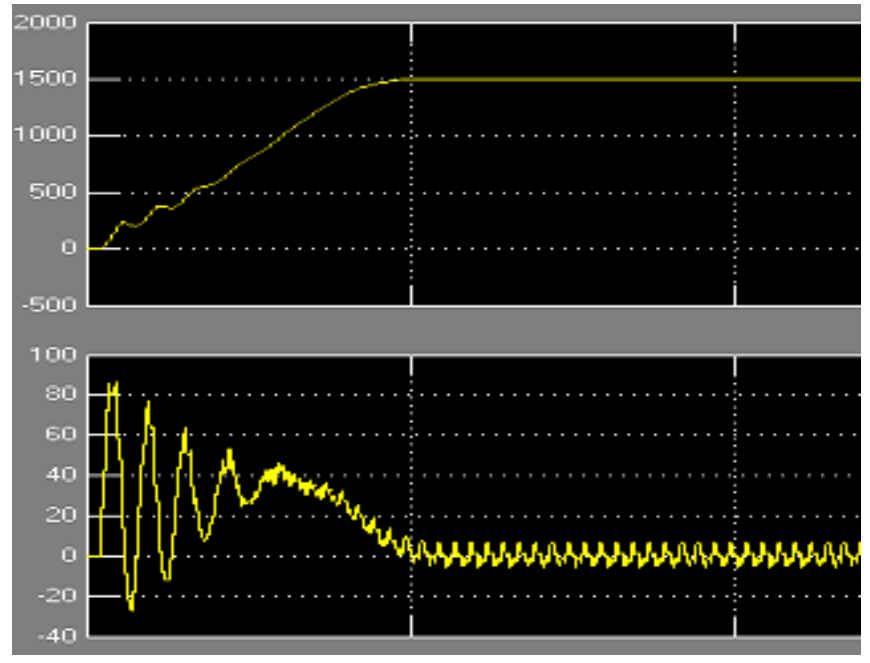

Fig 15:-Two level THIM INVERTER Speed and Torque

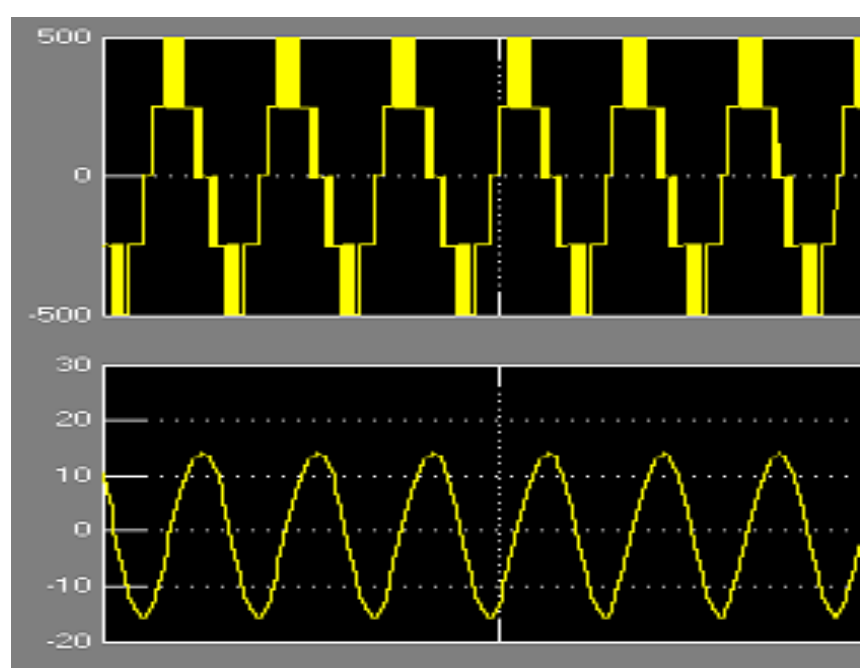

Fig 16:-Three level SPWM INVERTER RL load Line Voltage and Current

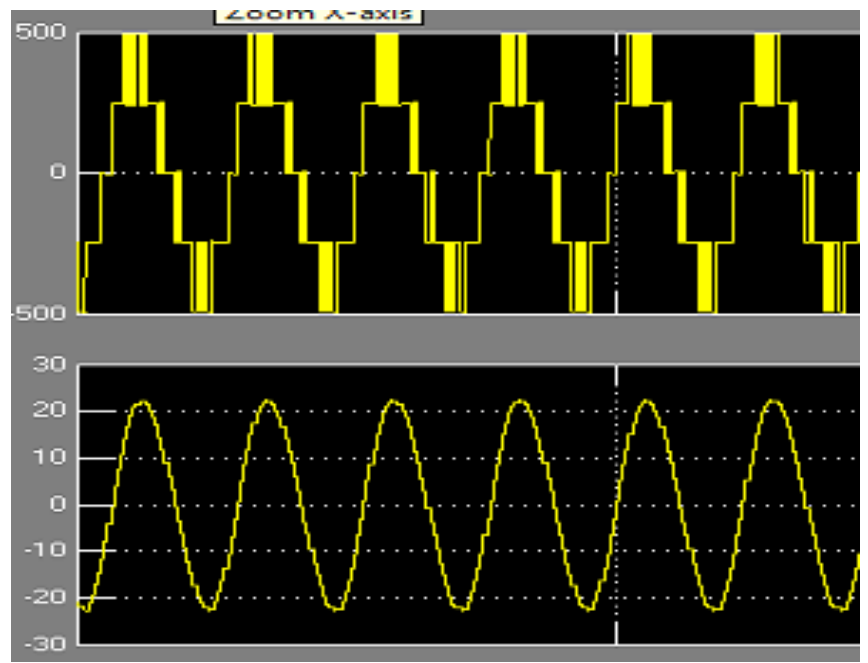

Fig 17:-Three level SPWM INVERTER RLC load Line Voltage and Current 


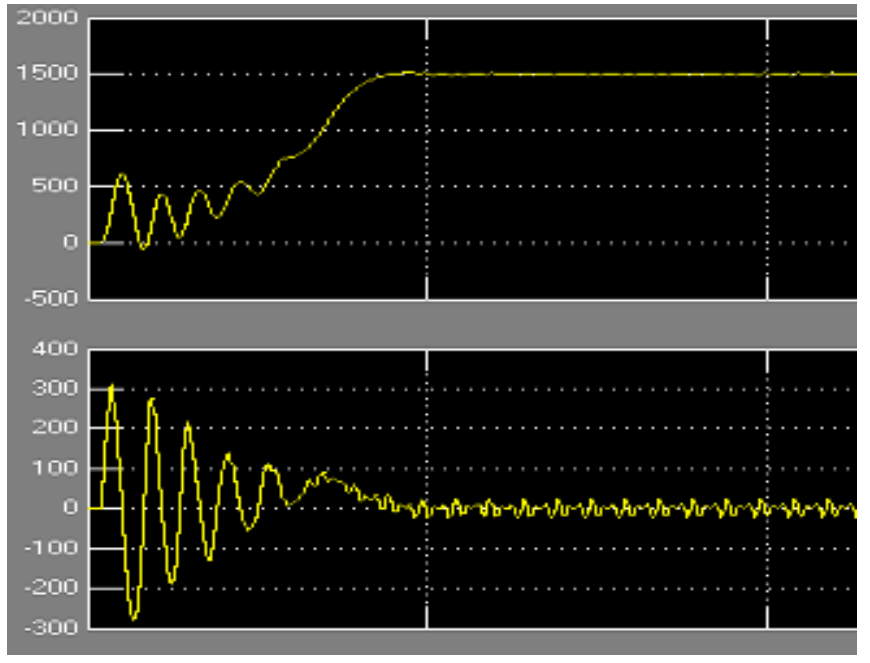

Fig 18:-Three level SPWM INVERTER Speed and Torque

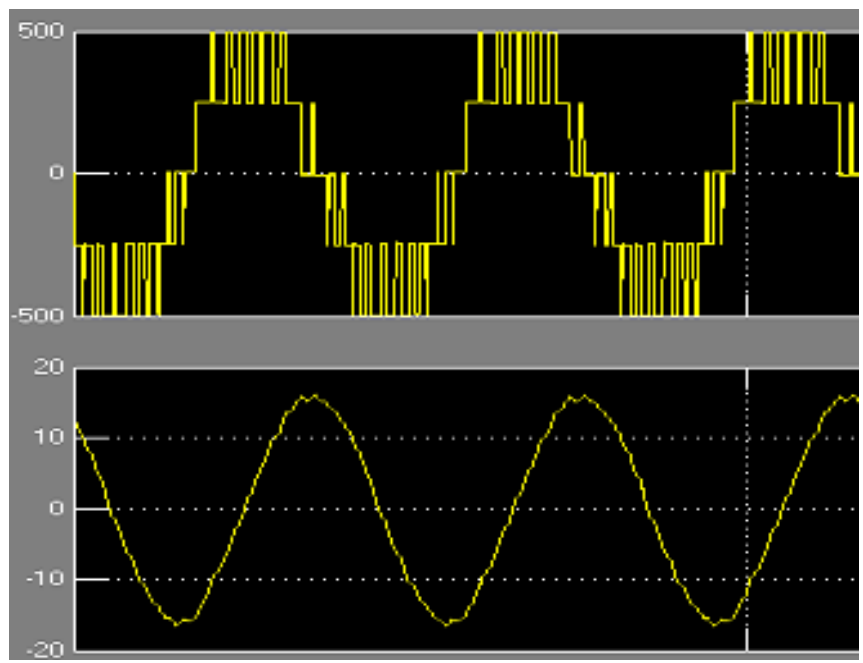

Fig 19:-Three level THIM INVERTER RL load Line Voltage and Current

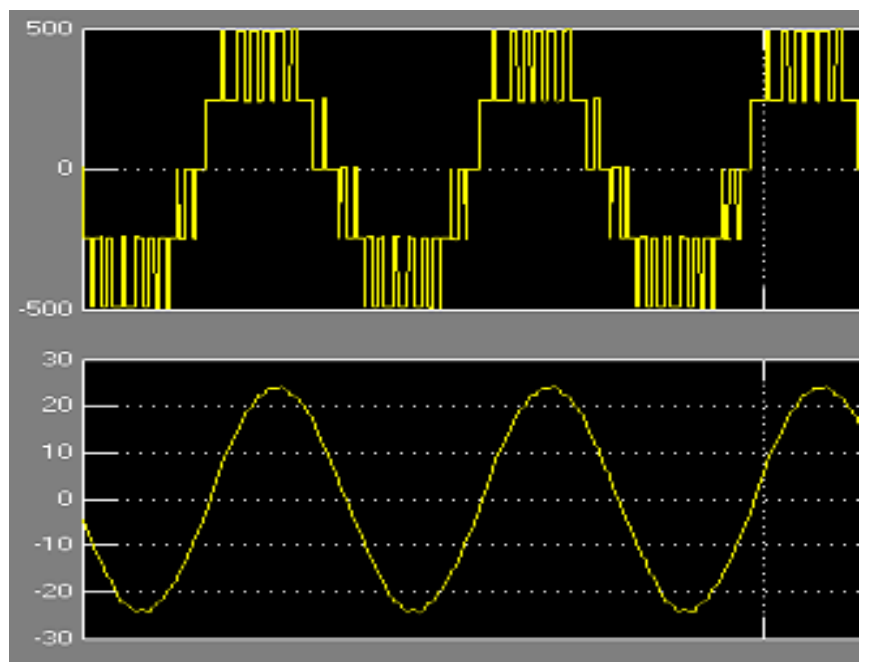

Fig 20:-Three level THIM INVERTER RLC load Line Voltage and Current

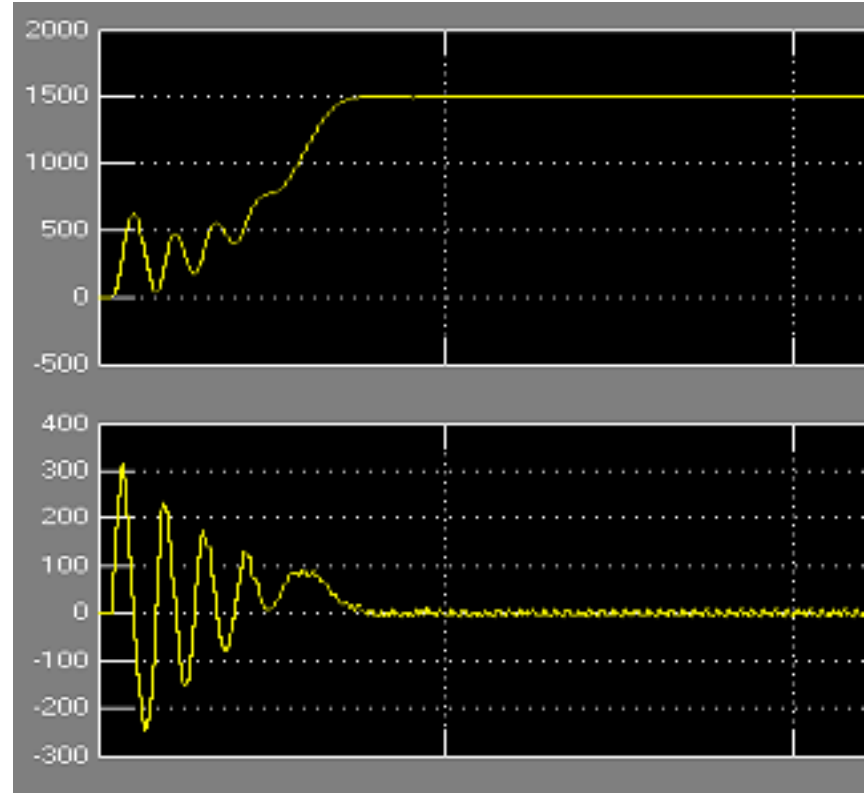

Fig 21:-Three level THIM INVERTER Speed and Torque

\section{RESULTS}

\begin{tabular}{|l|l|c|c|}
\hline LEVEL & TECHNIQUE & LOAD & THD\% \\
\hline \multirow{5}{*}{ TWO } & \multirow{2}{*}{ SPWM } & RL & 7.76 \\
\cline { 3 - 4 } & & RLC & 6.45 \\
\cline { 3 - 4 } & \multirow{4}{*}{ THIM } & IM & 44.66 \\
\hline \multirow{4}{*}{ THREE } & \multirow{2}{*}{ SPWM } & RL & 7.76 \\
\cline { 3 - 4 } & & RLC & 6.45 \\
\cline { 3 - 4 } & & IM & 44.66 \\
\cline { 3 - 4 } & \multirow{4}{*}{ THIM } & RL & 7.93 \\
\cline { 3 - 4 } & & RLC & 7.15 \\
\cline { 3 - 4 } & & IM & 10.58 \\
\cline { 3 - 4 } & & RL & 6.33 \\
\cline { 3 - 4 } & & RLC & 5.59 \\
\cline { 3 - 4 } & & IM & 7.41 \\
\hline
\end{tabular}

\section{CONCLUSION}

The SPWM technique and THIPWM technique is same for the RL, RLC and Induction Motor load for THD analysis. But the phase voltage of THIPWM technique is 1.15 times to the SPWM technique in Two level inverter. And in Three level Inverter the THIPWM technique is good as compare to SPWM technique. the THD of THIPWM technique is quite low is compare to SPWM technique. And one more advantage of the THIPWM technique is phase voltage of THIPWM technique over SPWM is 1.15 times of it. And the Speed And Torque Characteristics is always better in THIPWM technique as compare to SPWM while using to drive the Induction Motor, when it is used in Two level or in Three level voltage source Inverter. 


\section{REFERENCES}

[1] G.K. Dubey and C.R. Kasrabada, "Power Electronics and Drives", IETE Book Series, Vol. 1, TM HILL P.C. Ltd., New Delhi, 1993

[2] B. K. Bose, "Energy, environment and Advances in Power Electronics", IEEE Trans. on P.E. Vol.15, No.4 JULY 2000.

[3] P. C. Sen, "thyristorised DC Drive", New York: Wiley Interscience, 1981.

[4] P. Ramana, B.Santhosh Kumar, K.AliceMaryand M. SurayaKalavathi," Comparison of various PWM Techniques for Field Oriented Control VSI fed PMSM Drive," IJAREEIE, Vol.2, Issue.7, pp.29282936

[5] R. Kameswara Rao, P. Srinivas, M.V. Suresh Kumar," Design and analysis of variousInverters using different PWM Techniques", IJES, ISSN€:2319-1813 ISSN(p): 2319-1805.

[6] Raja Ram Kumar, Sunil Kumar,AlokYadav,"Comparion of PWM Techniques and Inverter Performance," IOSR Journal of Electrical and Electronics Engineering (IOSR-JEEE), ISSN:2278-1676 Vol 4, Issue 1 (Jan. - Feb. 2013), PP 18-22

[7] DUBEY, G.K., Power Semiconductor Controlled Drives. Englewood Cliffs, NJ: Prentice Hall, 1989

[8] DATTA, S.M.'Power Electronics \& Control". Reston, VA: Reston Publishing Co., Inc., 1985

[9] Microsemi User Guide, "Field Oriented Control of Permanent Magnet Synchronous Motors (PMSM)," www.microsemi.com

[10] N. Mohan, T.M. Undeland, etal." Power Converters, Applications and Design", $3^{\text {rd }}$ edition, Johan Wiley and Sons, New York, 2003

[11] Bimal K. Bose,'Modern Power Electronics and AC Drives," Prentice Hall, 2002.

[12] R. Krishnan, “ Electric Motor Drives-Modeling, Analysis, and Control," Prentice Hall, 2001.

[13] Muhammad H. Rashid, " Power Electronics Circuits, Devices, and Application" Third Edition. 